\title{
Phenotypic differences between esophageal and gastric intestinal metaplasia
}

\author{
M Blanca Piazuelo ${ }^{1}$, Salima Haque ${ }^{2}$, Alberto Delgado ${ }^{1}$, Joanna X Du ${ }^{1}$, Fred Rodriguez ${ }^{1,3}$ and \\ Pelayo Correa ${ }^{1}$ \\ ${ }^{1}$ Department of Pathology, Louisiana State University Health Sciences Center, New Orleans, LA, USA, \\ ${ }^{2}$ Department of Pathology, Tulane University Medical Center, New Orleans, LA, USA; ${ }^{3}$ Veterans Affairs \\ Medical Center, New Orleans, LA, USA
}

\begin{abstract}
Intestinal metaplasia is a cancer precursor in the esophagus and the stomach. Marked differences exist between the carcinogenic processes in the two locations in terms of natural history and clinical significance. We investigated biopsies from 52 patients with Barrett's esophagus and from 50 patients with gastric intestinal metaplasia in an attempt to throw light on their pathogenic processes. Morphologic characteristics, presence of Helicobacter pylori (H. pylori), and markers of differentiation, inflammation, and proliferation were evaluated by histochemical and immunohistochemical techniques. The area covered by incomplete type of intestinal metaplasia and the proportion of sulfomucins were significantly higher in the esophagus than in the stomach. Immunoreactivity with MUC1, MUC2, MUC5AC, Das-1, cytokeratins 7 and 20, inducible nitric oxide synthase and cyclooxygenase-2 antibodies was also significantly greater in Barrett's esophagus than in gastric intestinal metaplasia. In gastric intestinal metaplasia, the presence of MUC1, MUC5AC, Das-1 and cytokeratin 7 was restricted to areas with the incomplete type of metaplasia. Cell proliferation (Ki-67) was significantly higher in Barrett's esophagus than in gastric intestinal metaplasia. $\boldsymbol{H}$. pylori was absent in all of the patients with Barrett's esophagus, while it was present in $70 \%$ of the patients with gastric intestinal metaplasia. Our observations made clear that Barrett's esophagus shares some phenotypic characteristics with gastric intestinal metaplasia, leading us to suggest that both could arise in response to injuries with eventual carcinogenic potential. However, the progression to more advanced lesions could be modulated by the nature of the carcinogenic insult.
\end{abstract}

Modern Pathology (2004) 17, 62-74, advance online publication, 19 November 2003; doi:10.1038/modpathol.3800016

Keywords: Barrett's esophagus; gastric intestinal metaplasia; mucins; cytokeratins; Das-1; inducible nitric oxide synthase; cyclooxygenase-2; Ki-67

Gastric adenocarcinoma has decreased in incidence and mortality in the USA, but it remains the second most frequent cause of cancer deaths worldwide. ${ }^{1,2}$ In contrast, esophageal adenocarcinoma has recently displayed a striking increase in incidence, as reported in several countries, including the USA. $^{3-6}$ In the last decade, the incidence of adenocarcinoma in the lower esophagus, probably originating in Barrett's esophagus, has exceeded that of squamous cell carcinoma. ${ }^{4,5}$ According to a recent cohort analyses, the increase in esophageal adenocarcinoma is not shared by gastric cardia adenocarcinoma. $^{7}$

Correspondence: P Correa, Department of Pathology, Louisiana State University Health Sciences Center, 1901 Perdido St., New Orleans, LA 70112, USA. E-mail: correa@lsuhsc.edu

Received 12 May 2003; revised 16 July 2003; accepted 01 August 2003; published online 19 November 2003
Barrett's esophagus was originally described as 'columnar lined esophagus', ${ }^{8,9}$ and three types were recognized according to the epithelial cells found: fundic-type, cardiac-type (junctional) and specialized columnar epithelium. ${ }^{10}$ Currently, it has been accepted that the diagnosis of Barrett's esophagus requires the presence of specialized columnar epithelium with intestinal-type goblet cells. ${ }^{11,12}$

Intestinal metaplasia has been widely recognized as an associated risk factor and a probable precursor of both esophageal and gastric adenocarcinoma, ${ }^{13-19}$ but little is known about its pathogenesis. Multiple studies have shown changes in protein expression patterns in intestinal metaplasia, as well as in dysplasia and carcinoma in both esophagus and stomach. They include, among others, mucins, cytokeratins, and inflammatory enzymatic markers, such as inducible nitric oxide synthase and cyclooxygenase-2. 
Mucins are large, heavily glycosylated proteins present at the interface between many epithelia and their extracellular environment. ${ }^{20,21}$ They are produced by epithelial cells and are the main component of the gastrointestinal mucus gel layer. Normal esophageal mucosa displays MUC1 in the squamous epithelium, whereas MUC5B is expressed in the submucosal glands. ${ }^{22-24}$ Normal gastric mucosa expresses MUC1 and MUC5AC in the foveolar epithelium, whereas MUC6 is expressed in the deep glands. ${ }^{25,26}$ In Barrett's esophagus, neoexpression of gastric and intestinal mucins has been found..$^{22,24,27,28}$ In complete gastric intestinal metaplasia, neoexpression of the intestinal mucin MUC2 along with underexpression of normal gastric mucins have been reported, while incomplete gastric intestinal metaplasia has shown MUC1, MUC2 and MUC5AC expression. ${ }^{25,29,30}$ Esophageal and gastric adenocarcinomas have shown variable expression of gastric and intestinal mucins. ${ }^{24,31,32}$

Das-1 is a monoclonal antibody (formerly called $7 \mathrm{E} 12 \mathrm{H} 12)$ that was developed against a $40 \mathrm{kDa}$ colonic epithelial protein. ${ }^{33}$ More recently, Das-1 antibody was found to specifically recognize a $>200 \mathrm{kDa}$ colon epithelial protein that complexes with the $40 \mathrm{kDa}$ protein and acts as a chaperone to bring the $40 \mathrm{kDa}$ protein on colon epithelial surface. ${ }^{34}$ Several studies have shown Das-1 immunoreactivity with Barrett's metaplasia and Barrett's adenocarcinoma, ${ }^{35-37}$ as well as with gastric adenocarcinomas and carcinoma-associated intestinal metaplasia, ${ }^{38}$ but no reactivity has been found in normal esophageal, gastric or small intestinal mucosa. ${ }^{33,35}$

Cytokeratins, components of the cytoskeleton of epithelial cells, are intermediate-sized filaments that are expressed in different combinations. ${ }^{39,40}$ Cytokeratin 7 is considered a marker of ductal differentiation, present in multiple normal tissues but essentially absent from adult gastrointestinal and squamous cell epithelia. However, it is expressed in adult esophageal submucosal glands and ducts, ${ }^{41}$ and has been reported in fetal gastric glandular tissue. ${ }^{42,43}$ Cytokeratin 20, in contrast to cytokeratin 7, is expressed in normal foveolar gastrointestinal epithelium in gastric, small intestine and colonic mucosa. ${ }^{44}$

Recently, the pattern of expression of cytokeratins 7 and 20 in various preneoplastic and neoplastic entities, including Barrett's esophagus and intestinal metaplasia of the stomach, has been the subject of multiple studies. ${ }^{36,37,41,45-47}$ Controversial results have been published, especially regarding intestinal metaplasia in cardiac mucosa and gastroesophageal junction. ${ }^{36,37,41,45,48}$

Inducible nitric oxide synthase and cyclooxygenase- 2 are enzymatic mediators of inflammation and may be involved in epithelial cell growth. ${ }^{49}$ They are the inducible isoforms of nitric oxide synthase and cyclooxygenase, enzymes that regulate the production of nitric oxide and prostanoids, respectively.
Both enzymes have shown increased expression in several precancerous and cancerous processes in esophageal and gastric mucosa. ${ }^{50-55}$

Increase in proliferative activity is considered an early biological change in the carcinogenesis sequence of events. Ki-67 is a nuclear protein detectable in proliferating cells (late G1, S, G2, and $\mathrm{M}$ phases) but absent in resting cells (G0 phase). ${ }^{56}$ Although its function is not completely known, ${ }^{57}$ its expression has been considered as a reliable index of proliferation. Increase in proliferation has been observed in premalignant and malignant conditions of the esophagus and the stomach. ${ }^{5-61}$

This report explores the morphologic and immunophenotypic similarities and differences between intestinal metaplasia in the esophagus and in the stomach using histologic and immunohistochemical techniques as markers of mucin protein types, cytokeratins, inflammation and proliferation.

\section{Materials and methods}

\section{Tissue Specimens and Histochemistry}

A total of 102 adult patients attending gastroenterology services at three hospitals in New Orleans from 1991 to 2002 were enrolled in this comparative study. Esophageal specimens from 52 patients (including two resections) with Barrett's esophagus were obtained at Tulane University Medical Center and at Veterans Affairs Medical Center. Selection of patients with Barrett's esophagus was based on clinical and endoscopic criteria. Biopsies from the cardia, gastroesophageal and squamocolumnar junctions and tubular esophagus were obtained during endoscopy in these patients; however, after review of all the biopsies of each subject, only cases with intestinal metaplasia proximal to the squamocolumnar junction were selected. Endoscopic gastric biopsies from 50 patients with intestinal metaplasia distal to the cardia (corpus and antrum) were obtained at Louisiana State University Hospital.

Specimens were fixed in buffered $10 \%$ formalin and embedded in paraffin. Serial $4 \mu \mathrm{m}$-thick sections were cut from each paraffin block and mounted on poly-L-lysine coated Probe-On slides (Fisher Biotech) for histochemistry and immunohistochemistry. Staining with hematoxylin and eosin using standard techniques was performed.

Barrett's esophagus was defined as histologic evidence of intestinal metaplasia within the esophagus, and characterized by presence of goblet cells. Gastric intestinal metaplasia was defined as presence of intestinal metaplasia within corpus or antral mucosa. Cardiac intestinal metaplasia was not included in our study. Presence of neutral, sialic and sulfated mucins was evaluated with Alcian blue, $\mathrm{pH}$ 2.5/periodic acid-Schiff ${ }^{62}$ and with Alcian blue/ high-iron diamine ${ }^{63}$ stains. The presence of Helicobacter pylori (H. pylori) was assessed by modified Steiner silver stain. ${ }^{64}$ 
All the histochemical and immunochemical stains were carried out simultaneously for all gastric and esophageal tissues to assure identical reagents dilution, timing and temperature.

\section{Immunohistochemistry}

Tissue sections from every paraffin block were immunostained with antibodies for MUC1, MUC2, MUC5AC, MUC6, cytokeratins 7 and 20, Das-1, Ki67, inducible nitric oxide synthase and cyclooxygenase-2. Mucins and cytokeratins antibodies were obtained from Novocastra (Burlingame, CA, USA), Ki-67 (MIB-1) from Biocare Medical (Walnut Creek, CA, USA), inducible nitric oxide synthase from Zymed Laboratories (San Francisco, CA, USA) and cyclooxygenase-2 from Cayman Chemical Co. (Ann Arbor, MI, USA). Das-1 antibody was kindly provided by Dr Kiron M Das (Robert Wood Johnson Medical School, NJ, USA).

Briefly, after overnight heating at $37^{\circ} \mathrm{C}$, the sections were deparaffinized in xylene and rehydrated in graded alcohols (100 and 95\% ethanol, two and three changes, respectively, 3 min each). Endogenous peroxidase was blocked by heating the slides in a hydrogen peroxide solution $(3 \%)$ for $5 \mathrm{~min}$ in a microwave oven ( $30 \%$ power). The slides were arranged in pairs and all immunostainings were performed using capillary action. Pretreatment with trypsin ( $1 \mathrm{mg}$ in $150 \mathrm{ml}$ Tris- $\mathrm{HCl}, 0.05 \mathrm{M}$, pH 7.6) solution for $15 \mathrm{~min}$ at room temperature was performed, before an antigen retrieval technique using citrate buffer (0.01 M, pH 6.0) and microwave heating was applied. Type, specificity and dilution of the antibodies used are listed in Table 1. The tissues were incubated with primary antibodies overnight at $4^{\circ} \mathrm{C}$ in humid chamber. After washing, incubation with biotinylated secondary antibodies was performed for $30 \mathrm{~min}$ at room temperature. Sections were rinsed and incubated with streptavidin-biotin-peroxidase complex (Strept-ABComplex, Dako, Carpinteria, CA, USA) for $30 \mathrm{~min}$ at room temperature. Diaminobenzidine (SIGMA FAST

Table 1 Antibodies, type, specificity and dilutions

\begin{tabular}{llll}
\hline Antibody & Type $^{\mathrm{a}}$ & Specificity & Dilution \\
\hline HMFG1 & Mouse mAb & MUC1 & $1: 25$ \\
HMFG2 & Mouse mAb & MUC1 & $1: 25$ \\
Ccp58 & Mouse mAb & MUC2 & $1: 50$ \\
CLH2 & Mouse mAb & MUC5AC & $1: 50$ \\
CLH5 & Mouse mAb & MUC6 & $1: 50$ \\
Das-1 & Mouse mAb & Colonic epithelial protein & $1: 25$ \\
OV-TL 12/30 & Mouse mAb Cytokeratin 7 & $1: 25$ \\
Ks 20.8 & Mouse mAb Cytokeratin 20 & $1: 25$ \\
iNOS & Rabbit pAb & iNOS & $1: 300$ \\
CX-229 & Mouse mAb Cyclooxygenase-2 & $1: 100$ \\
MIB-1 & Mouse mAb & Ki-67 & $1: 30$ \\
\hline
\end{tabular}

a $\mathrm{mAb}$, monoclonal antibody; pAb, polyclonal antibody; iNOS, inducible nitric oxide synthase.
DAB Peroxidase Substrate Tablet Set, Sigma-Aldrich, St Louis, MO, USA) was used as a chromogen. With the exception of Ki-67, which was counterstained with methyl green, all the remaining stains were counterstained with hematoxylin. Finally, the sections were dehydrated in graded alcohols, cleared in xylene and mounted with permanent mounting medium. Negative controls were performed by omitting the primary antibody.

\section{Statistical Analysis}

Statistical analysis was performed and graphics were drawn using Statistical Package for Social Sciences (SPSS) and Statistical Analysis System (SAS) software. T-test or Fisher's exact test for comparison of results was utilized as applicable. The level of significance was set at $P<0.05$.

\section{Results}

\section{Patients}

The mean age of the patients with Barrett's esophagus $(n=52)$ was 62.6 years $( \pm$ s.d. 10.3$)$, while the mean age of the patients with gastric intestinal metaplasia $(n=50)$ was 55.5 years $( \pm$ s.d. 10.6). Detailed demographic data are shown in Table 2.

\section{Histological Assessment}

Histochemical and immunohistochemical staining were assessed by light microscopy. A semiquantitative $0-3$ scale was applied in every case according to the proportion of metaplastic epithelium displaying incomplete intestinal metaplasia, proportion of sulfomucins among acid mucins, and proportion of metaplastic epithelium expressing immunoreactivity (MUCs, Das-1, cytokeratins, inducible nitric oxide synthase and cyclooxygenase-2) as follows: $0=0-5 \% ; \quad 1=6-34 \% ; 2=35-64 \%$; and $3=65-$ $100 \%$. Areas $\leq 5 \%$ were considered negative.

Table 2 Age distribution by diagnosis, hospital and sex

\begin{tabular}{|c|c|c|c|c|c|c|}
\hline & \multicolumn{4}{|c|}{ Barrett's esophagus } & \multirow{2}{*}{\multicolumn{2}{|c|}{$\begin{array}{c}\text { Gastric } \\
\text { intestinal } \\
\text { metaplasia }\end{array}$}} \\
\hline & \multicolumn{2}{|c|}{ Tulane UMC } & \multicolumn{2}{|r|}{$V A M C$} & & \\
\hline & $\mathrm{n}$ & $A g e^{\mathrm{a}}$ & $\mathrm{n}$ & Age & $\mathrm{n}$ & Age \\
\hline Males & 18 & $59.4(9.9)$ & 26 & $66.5(9.3)$ & 23 & $57.0(10.4)$ \\
\hline Females & 8 & $57.0(11.0)$ & & - & 27 & $53.7(10.7)$ \\
\hline
\end{tabular}

Tulane UMC; Tulane University Medical Center; VAMC, Veterans Affairs Medical Center; LSU Hospital, Louisiana State University Hospital.

${ }^{\mathrm{a}}$ Mean age in years and standard deviation (s.d.). 

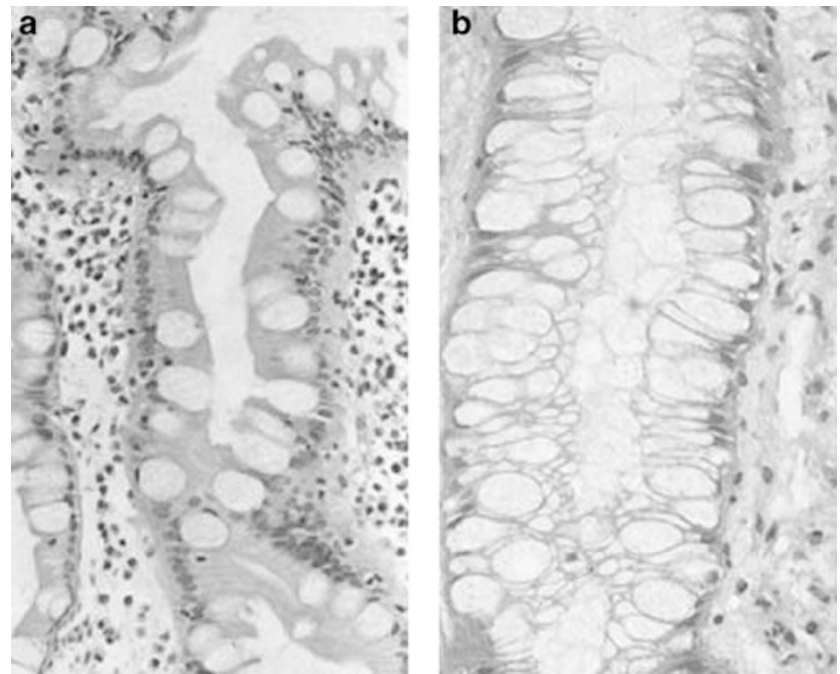

Figure 1 Classification of intestinal metaplasia in H-E stain. (a) Complete type with well-defined goblet cells alternating with eosinophilic enterocytes displaying well developed brush border. (b) Incomplete type showing goblet/mucous cells of varying sizes and shapes, and absence of brush border.

Intestinal metaplasia was classified as complete (small intestinal or type I) or incomplete (colonic or types II and III) based on hematoxylin-eosin (H-E) stain. Complete intestinal metaplasia was characterized by the presence of absorptive enterocytes with eosinophilic cytoplasm with a well-developed brush border, alternating with well-defined goblet cells (Figure 1a). Incomplete intestinal metaplasia was characterized by columnar cells without a clear brush border and by the presence of many goblet/ mucous cells of varying sizes and shapes (Figure 1b). The area occupied by complete or incomplete intestinal metaplasia was visually estimated as a percentage of the total metaplastic area present in each case.

Of the 52 patients with Barrett's esophagus 28 $(54 \%)$ showed areas of complete intestinal metaplasia. In average, $89 \%$ of the metaplastic area in Barrett's esophagus patients was considered of incomplete type, whereas the remaining $11 \%$ was of the complete type. In contrast, in gastric intestinal metaplasia, the mean proportional area of incomplete and complete intestinal metaplasia was 18.6 and $81.4 \%$, respectively. This difference between the two groups of patients was statistically significant $(P<0.001)$.

\section{Histochemistry}

Mucin histochemistry was evaluated with Alcian blue, $\mathrm{pH}$ 2.5/periodic. acid-Schiff and Alcian blue/ high-iron diamine stains. Most $(67.3 \%)$ cases of Barrett's metaplasia had some degree of sulfated mucins, demonstrable by brown staining in the Alcian blue/high-iron diamine stain (Figure 2a), whereas most $(77.6 \%)$ cases of gastric intestinal metaplasia had only sialomucins (Figure 2b). The proportion of sulfated vs sialic mucins was visually assessed in Alcian blue/high-iron diamine stain in every case and an approximate percentage for each was tabulated. The mean percentage of acid mucins estimated to correspond to sulfomucins was $26.4 \%$ for Barrett's esophagus and $5.3 \%$ for gastric intestinal metaplasia $(P<0.001)$. Areas of periodic acidSchiff-positive cells, indicating presence of neutral mucins were found in all of cases of Barrett's esophagus.

$H$. pylori was not observed by Steiner silver stain in the specimens from patients with Barrett's esophagus, whereas it was present in $70 \%$ of the patients with gastric intestinal metaplasia.

\section{Immunohistochemistry}

\section{Mucins}

MUC1 expression was evaluated by two different antibodies: HMFG1 and HMFG2. ${ }^{65}$ MUC1 was expressed in the superficial two-thirds of the esophageal squamous epithelium. In non-metaplastic gastric mucosa, foveolar epithelium and a few mucous glands in antrum and cardia also expressed MUC1. In the glands of the oxyntic region, it was observed in chief and parietal cells. Barrett's esophagus displayed diffuse expression of MUC1 in both columnar and goblet cells (strong and consistent with HMFG2 antibody, variable with HMFG1) with exception of small foci with complete metaplasia, where MUC1 expression was absent or faint (Figure 2c). In complete intestinal metaplasia of the stomach there was no expression of MUC1 (Figure 2d), whereas it was consistently observed in incomplete intestinal metaplasia (Figure 2e). The MUC1 immunostaining pattern in columnar cells was different depending on the antibody used: strong and diffuse in the cytoplasm with HMFG2 and weak-to-moderate staining in apical membrane and/or cytoplasm with HMFG1. Goblet cells showed basolateral staining with both antibodies.

MUC2 immunostaining was absent in normal gastric and esophageal mucosa. Its expression was consistently strong in Barrett's metaplasia (Figure $2 \mathrm{f})$, where $100 \%$ of the cases showed expression in goblet cells and $87 \%$ of the cases in columnar cells. In gastric intestinal metaplasia, MUC2 was present in goblet cells in $94 \%$ of the cases and in columnar cells in $33 \%$ of the cases. However, in gastric intestinal metaplasia the staining intensity and pattern differed according to the type of intestinal metaplasia: In complete type, MUC2 was weakly expressed in most goblet cells and in rare columnar cells (Figure 2g), while in incomplete type, MUC2 displayed strong staining in goblet cells and in some columnar cells (Figure $2 \mathrm{~h}$ ).

MUC5AC was expressed in the foveolar cells and in the gland necks of the normal gastric mucosa. It was absent in the normal squamous-lined 


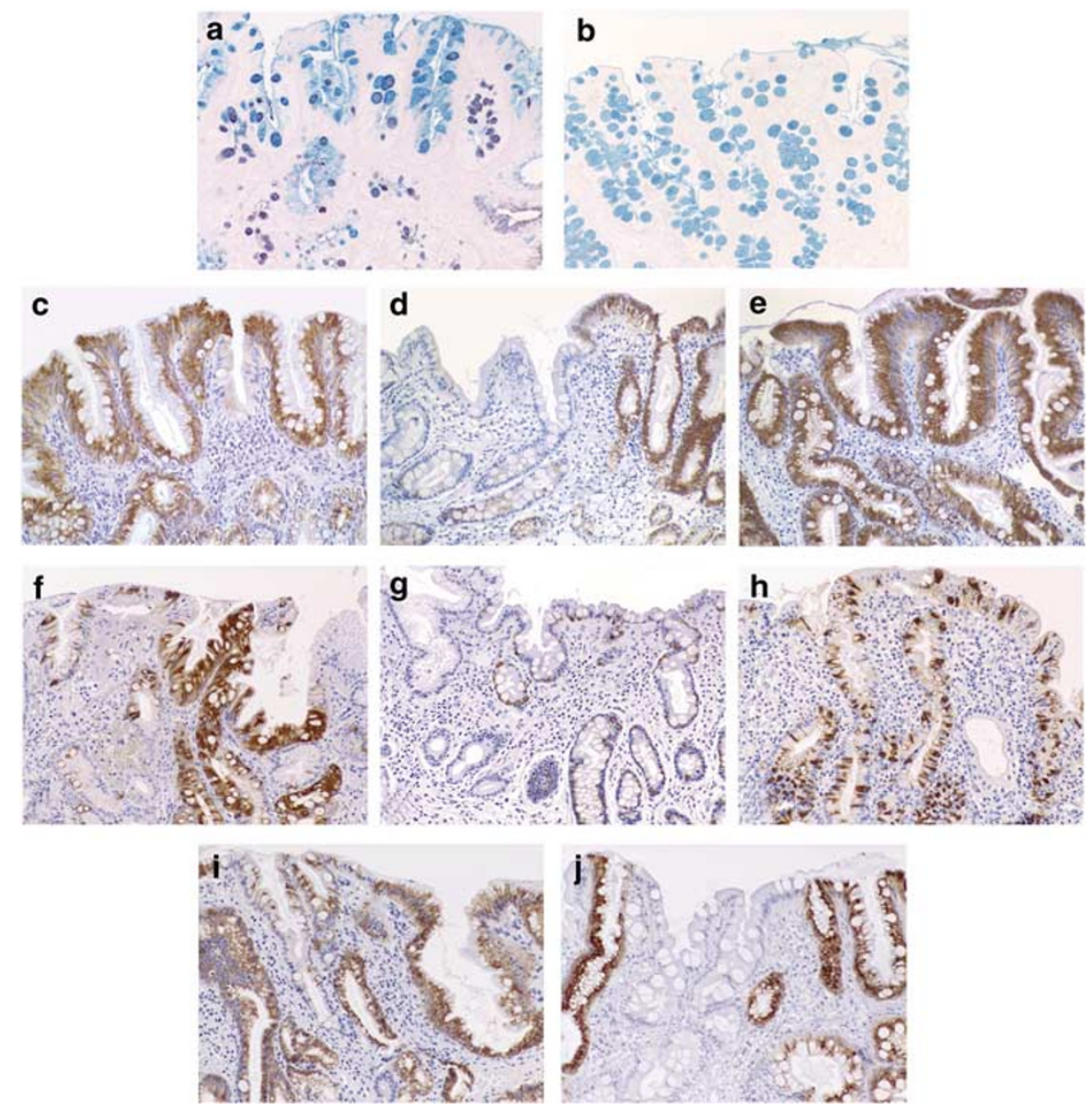

Figure 2 Histochemical and immunohistochemical stainings of Barrett's esophagus (A, C, F and I) and intestinal metaplasia of the stomach (B, D, E, G, H and J). (a, b) Alcian blue/high iron diamine staining showing sialomucins (blue) in both, and sulfomucins (brown) mostly observed in Barrett's esophagus. (c-e) MUC1 (HMFG2), strongly expressed in Barrett's epithelium (C) and in incomplete gastric intestinal metaplasia (E). Nonmetaplastic antral mucosa expresses MUC1 whereas it is absent in complete metaplasia (D). (f-h) MUC2 expression, strong in Barrett's epithelium (F) contrasting with faint in gastric complete intestinal metaplasia (G) and moderate in gastric incomplete intestinal metaplasia (H). (i, j) MUC5AC is expressed in Barrett's epithelium (I), absent in complete type and present in incomplete type of gastric intestinal metaplasia $(\mathrm{J})$.

esophagus. In intestinal metaplasia, MUC5AC expression was observed in both goblet and columnar cells in $100 \%$ of patients with Barrett's esophagus (Figure 2i) and in $40 \%$ of patients with gastric intestinal metaplasia. Furthermore, its expression pattern was different according to the type of intestinal metaplasia in both esophagus and stomach: MUC5AC was expressed in incomplete type and absent in complete type (Figures 2i and j).

MUC6 was expressed in the deep glands of the normal gastric mucosa and absent in both the superficial gastric epithelium and the normal esophageal tissues. MUC6 expression was absent in any type of intestinal metaplasia in either esophageal or gastric tissues. Only in few patients with Barrett's metaplasia, MUC6 was observed in some deep glands, which did not display intestinal phenotype (Figure 3a) it appears that those deep glands may not represent the same lineage as Barrett's epithelium. These glands were positive for neutral mucins with periodic acid-Schiff staining, suggesting gastric cell lineage. In gastric intestinal metaplasia cases, MUC6 was seen in the remaining original nonmetaplastic glands of the stomach (Figure $3 \mathrm{~b}$ ).

Das-1

In nonmetaplastic tissues, Das-1 immunoreactivity was absent in esophageal squamous epithelium and gastric mucosa, but present in ductal epithelium of esophageal glands. In Barrett's esophagus, strong Das-1 immunostaining was observed in goblet and columnar cells in 96 and $94 \%$ of the cases, respectively (Figure 3c). Das-1-positive goblet cells were similarly distributed in superficial and deep epithelium. Columnar cells in Barrett's esophagus were positive in superficial epithelium in $7 \%$ of the cases, $86 \%$ deep, and $7 \%$ in both compartments. In gastric intestinal metaplasia, goblet and columnar cells positive for Das-1 were observed in 9 and $19 \%$ of the cases, respectively, only in areas with incomplete intestinal metaplasia (Figure 3e). 

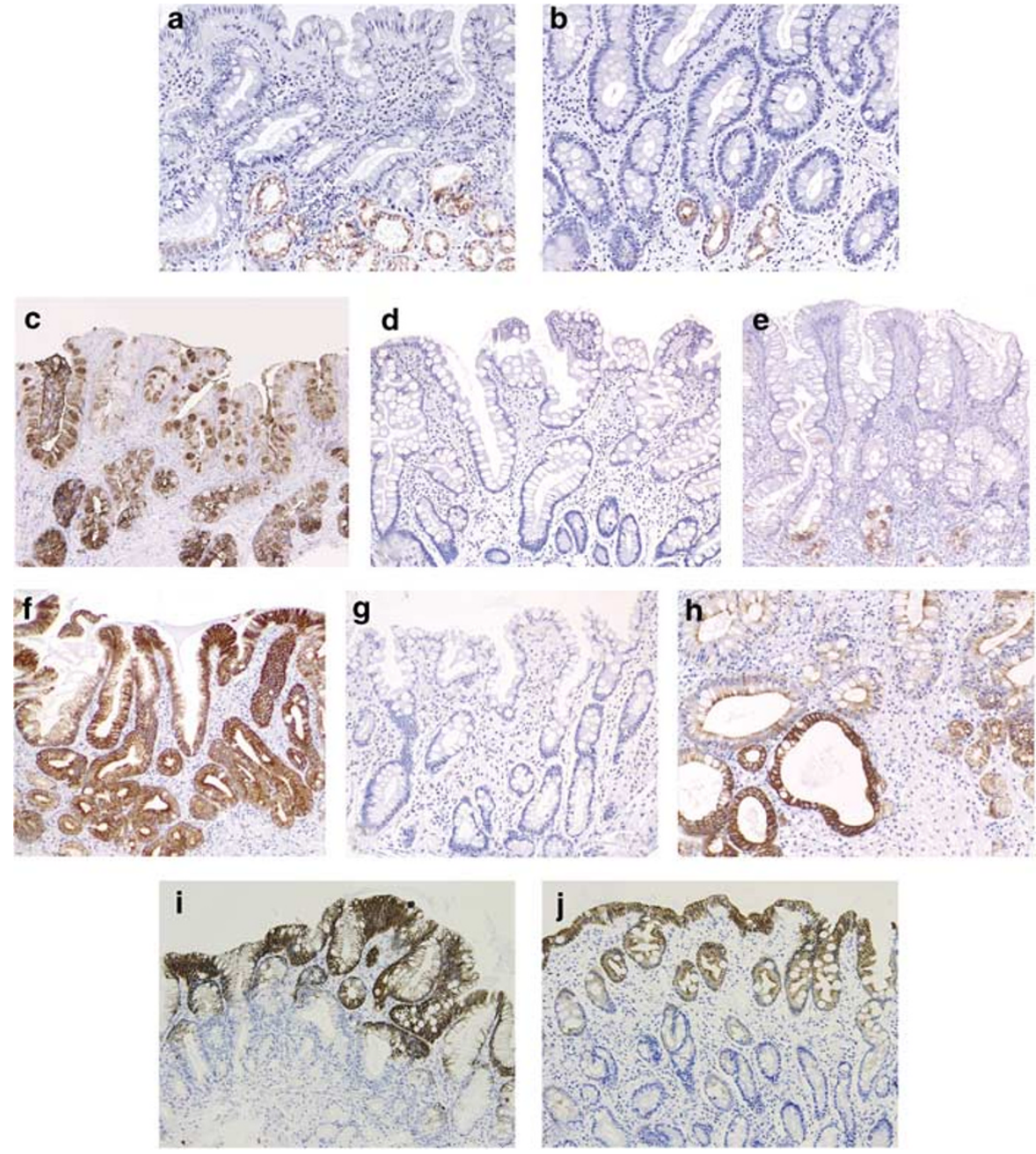

Figure 3 Immunohistochemical stainings of Barrett's esophagus (A, C, F and I) and intestinal metaplasia of the stomach (B, D, E, G, H and J). (a, b) MUC6 expression in deep glands without intestinal phenotype in both organs. (c-e) Das-1 immunoreactivity, strong in Barrett's epithelium (C), negative in gastric complete intestinal metaplasia (D) and scarce in gastric incomplete intestinal metaplasia (E). (f-h) Cytokeratin 7 expression, strong in Barrett's esophagus (F), absent in gastric complete intestinal metaplasia (G), and moderate in gastric incomplete intestinal metaplasia $(\mathrm{H})$, with higher expression in deep microcysts. (i, j) Cytokeratin 20 showing superficial expression in both entities.

Das-1-positive columnar cells in gastric intestinal metaplasia were always located in either hyperproliferative necks or in deep glands.

Das-1-positive deep microcysts were observed in four patients with Barrett's esophagus and in one patient with incomplete gastric intestinal metaplasia.

\section{Cytokeratins 7 and 20}

In nonmetaplastic tissues, strong cytokeratin 7 expression was observed in ductal epithelium of submucosal esophageal glands, and to a lesser degree in nonmetaplastic cardia from patients with Barrett's esophagus; corpus and antral mucosa were both negative. Cytokeratin 7 expression was strong and diffuse, involving the entire Barrett's epithelium in $100 \%$ of the cases (Figure 3f). Both goblet and columnar cells were stained. In contrast, only $10 \%$ of the gastric intestinal metaplasia cases were considered positive; cytokeratin 7 expression was only observed in areas of incomplete metaplasia and was seen either in the superficial epithelium, deep glands, or both compartments. In addition, cytokeratin 7 was also strongly expressed in deep microcysts in four patients with Barrett's esophagus and in three subjects with antral intestinal metaplasia (Figure 3h).

Cytokeratin 20 was expressed in superficial foveolar epithelium in nonmetaplastic gastric mucosa (cardia, corpus and antrum) and absent in esophageal normal mucosa. In Barrett's esophagus and in gastric intestinal metaplasia, 100 and $79 \%$ of the cases were positive for cytokeratin 20, respectively. Goblet and columnar cells were stained in similar proportion. Although the cytokeratin 20 expression was displayed in higher percentage of cells in Barrett's metaplasia than in gastric intestinal metaplasia, it was always superficial (Figures $3 \mathrm{i}$ and $\mathrm{j}$ ). 

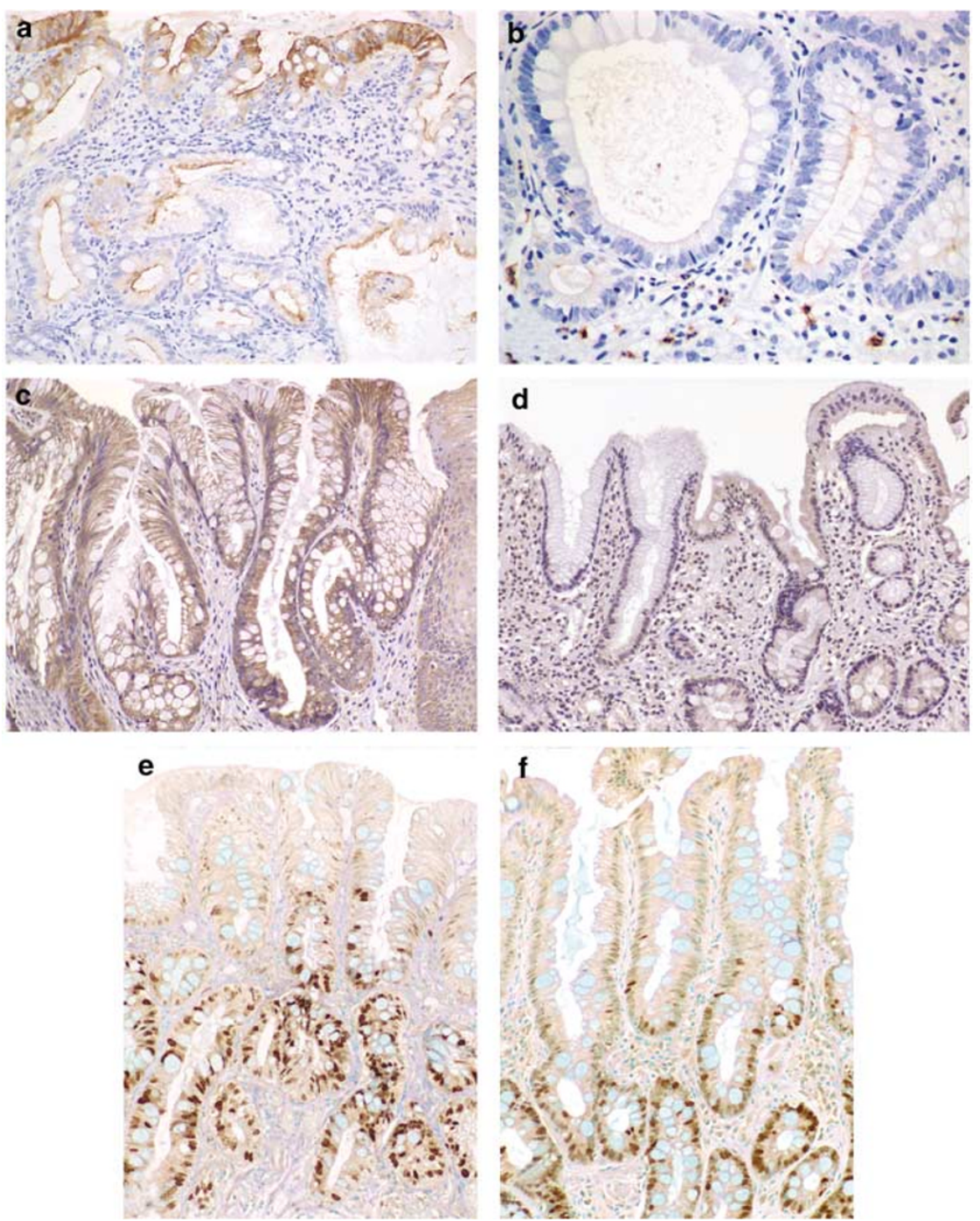

Figure 4 Immunohistochemical stainings of Barrett's esophagus (A, C and E) and intestinal metaplasia of the stomach (B, D and F). (a, b) Inducible nitric oxide synthase, strongly expressed in cytoplasm and apical surface of epithelial cells in Barrett's esophagus (A) and weak in apical surface in gastric incomplete intestinal metaplasia (B). Stromal polymorphonuclear neutrophils are positively stained. (c, d) Cyclooxygenase-2 shows strong expression in Barrett's epithelium and moderate in adjacent squamous epithelium (C) and weaker expression in gastric intestinal metaplasia (D). (e, f) Ki-67 (MIB-1), showing superficial expansion of the proliferative zone and higher nuclear labelling index in Barrett's esophagus (E) than in gastric intestinal metaplasia (F).

\section{Inflammatory Markers}

Inducible nitric oxide synthase expression was observed in polymorphonuclear leukocytes and macrophages in the stroma in both Barrett's esophagus and gastric intestinal metaplasia. Epithelial staining was present only in areas with intestinal metaplasia and in small foci with dysplastic changes. While $58 \%$ of the Barrett's esophagus cases had epithelial cells positive for inducible nitric oxide synthase, only $25 \%$ of the gastric ones showed some degree of epithelial staining. Some inducible nitric oxide synthase-positive Barrett's esophagus cases (18\%) displayed strong epithelial staining (Figure 4a), whereas all of the inducible nitric oxide synthase-positive gastric intestinal metaplasia cases were weakly (Figure 4b) or moderately stained.
Furthermore, different epithelial staining pattern was observed: Barrett's esophagus showed inducible nitric oxide synthase expression at the apical surface and/or in the cytoplasm, while in gastric intestinal metaplasia it was expressed only at the apical surface.

Cyclooxygenase-2 immunostaining was observed in stromal macrophages and endothelial cells in the gastric and esophageal metaplastic tissues. In Barrett's esophagus, cyclooxygenase-2 immunoreactivity was present in epithelial cells in $100 \%$ of the cases, whereas it was observed in $84 \%$ of gastric intestinal metaplasia cases. Barrett's intestinal metaplasia displayed stronger staining (Figure 4c) and greater proportion of stained cells than gastric intestinal metaplasia (Figure 4d). 

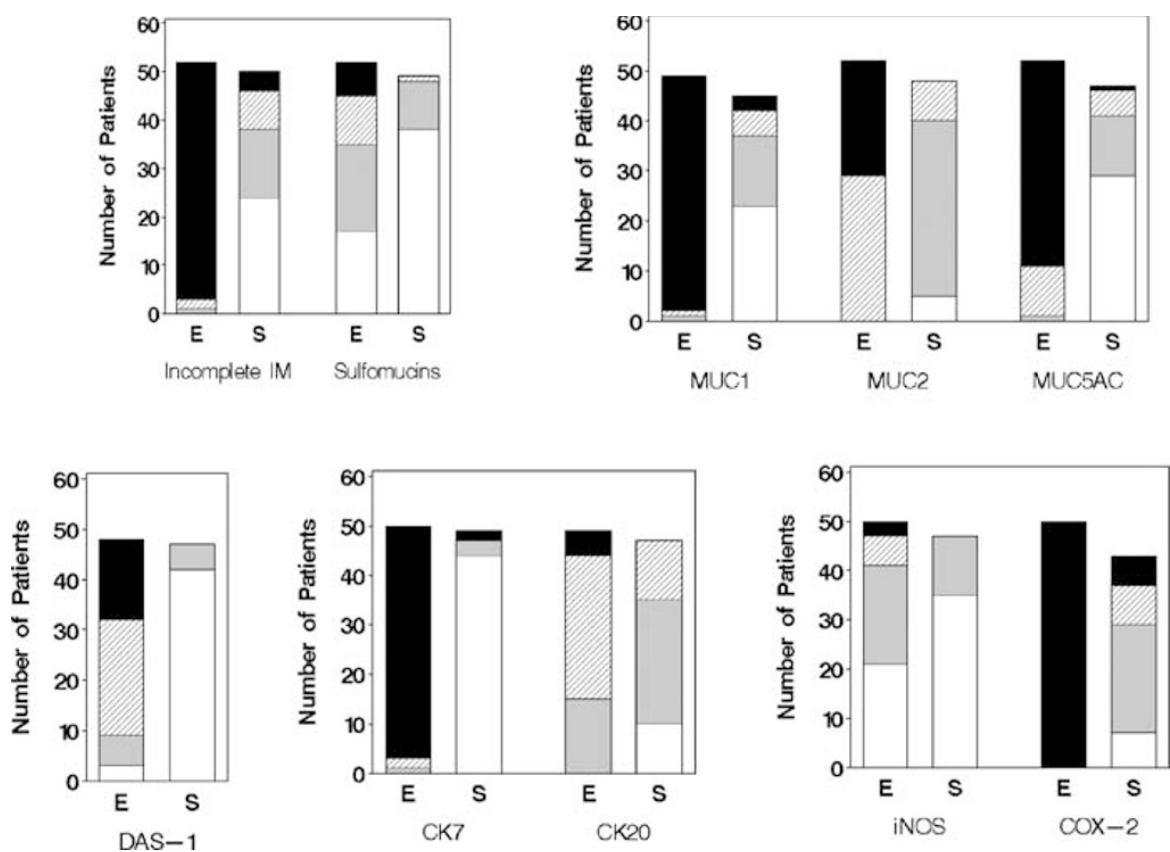

Figure 5 Phenotypic characteristics in intestinal metaplasia in esophagus (E) and stomach (S). Percentage of metaplastic epithelial cells immunostained (including goblet and columnar cells together) is classified as 0 (white): 0-5\%; 1 (gray): 6-34\%; 2 (cross-hatched): 3564\%; and 3 (black): 65-100\%. (MUC1 data shown correspond to HMGF2 antibody.)

With exception of MUC6, which was negative in all cases, the remaining markers (HMFG1, HMFG2, MUC2, MUC5AC, Das-1, cytokeratins 7 and 20, inducible nitric oxide synthase and cyclooxygenase2) showed significantly higher immunoreactivity in Barrett's esophagus than in gastric intestinal metaplasia $(P=0.001$ for inducible nitric oxide synthase; $P<0.001$ for the other markers). Results are shown in Figure 5.

\section{Proliferation}

Nuclear staining for Ki-67 was assessed in 20 cases with gastric intestinal metaplasia and in 20 with Barrett's esophagus. Only well-oriented mucosa biopsies were analyzed. Areas showing dysplasia or indefinite for dysplasia were not assessed. They were identified according to established criteria: increase in the nucleus/cytoplasm ratio, nuclear hyperchromatism, nuclear stratification and loss of polarity. ${ }^{11,12,66,67}$ Moderate or strong Ki-67 nuclear staining was considered positive. Selected metaplastic glands were divided halfway in superficial and deep compartments and positive and negative epithelial nuclei were counted separately in each compartment. One to six glands per case were analyzed. The Ki-67 labelling index was calculated as the percentage (\%) of positive nuclei among the total number of nuclei in each compartment. In both compartments, the mean labelling index was significantly higher in Barrett's mucosa than in gastric intestinal metaplasia $(P<0.001)$. The superficial compartment showed superficial expansion of the replication zone in Barrett's mucosa compared to gastric intestinal metaplasia (mean Ki-67 labelling indexes $=8.5$ and $3 \%$, respectively). Mean Ki-67 labelling indexes in the deep compartment were 48.4 and $35 \%$ for Barrett's esophagus and gastric intestinal metaplasia, respectively (Figure 4e and f).

\section{Helicobacter pylori Infection}

All of the Barrett's esophagus tissues were negative for $H$. pylori and $35(70 \%)$ of the patients with gastric intestinal metaplasia were positive, evaluated in modified Steiner silver stain.

Comparative analyses between $H$. pylori-infected $(n=35)$ and $H$. pylori-uninfected patients $(n=15)$ with gastric intestinal metaplasia were made. $H$. pylori infection was significantly associated with greater proportion of incomplete-type intestinal metaplasia $(23 \%$ in positive vs $8 \%$ in negative subjects, $P=0.017)$ and higher expression of MUC1 with HMFG2 antibody $(P=0.004)$. There were no statistically significant differences when HMFG1 (MUC1), MUC2, MUC5AC, Das-1, cytokeratins 7 and 20, inducible nitric oxide synthase and cyclooxygenase-2 immunostains were compared between the two groups. Five out of the 50 patients with gastric intestinal metaplasia expressed cytokeratin 7, and all of them were positive for $H$. pylori.

\section{Discussion}

The aim of the study was to attempt to clarify the reasons behind the marked differences in the clinical and prognostic impact of intestinal metaplasia in the esophagus and in the stomach. The 
results summarized below are interpreted in the light of some of the controversies surrounding the subject.

Historically, the nomenclature applied to the phenotypic subtypes of intestinal metaplasia has been confusing. There is general agreement that such phenotypes differ in terms of their natural history and prognostic significance. Cross-sectional and cohort follow-up studies have shown that the loss of the gastric glands (atrophy) is replaced by a metaplastic process which is multifocal and becomes more extensive as age advances, apparently due to confluence of neighboring foci. ${ }^{68,69}$ In young subjects with less extensive areas of gastric glands replaced by intestinal phenotypes, the metaplastic glands closely resemble the normal small intestine. They secrete exclusively sialomucins and contain the 'complete' set of normal digestive enzymes such as sucrase, trehalase and alkaline phosphatase. ${ }^{70}$ Because of these characteristics they have been assigned the names of 'small intestinal', 'type I' or 'complete' metaplasia. ${ }^{16,70,71}$ In older patients with extensive metaplasia, foci resembling enterocolic glands, without some of the normal digestive enzymes (trehalase and alkaline phosphatase) and secreting sulfated mucins are observed. This phenotype has been called 'enterocolic', 'colonic', 'type III' or 'incomplete' metaplasia, and is frequently associated with areas of dysplasia and carcinoma. ${ }^{16,70-72}$ Because of the multitude of names, there has been a tacit international agreement to refer to the two phenotypes following the Japanese nomenclature based on the presence ('complete') or absence ('incomplete') of digestive enzymes. ${ }^{73}$ This choice of nomenclature is somewhat unfortunate because it is counterintuitive since it may imply that the metaplasia is first 'incomplete' and may evolve to 'complete'. Clinical and epidemiologic observations, including follow-up studies indicate that the natural history of the process goes in opposite direction: complete (type I) intestinal metaplasia may evolve to incomplete metaplasia (type III). ${ }^{74}$ Some patients with incomplete metaplasia have shown progression to dysplasia and early gastric cancer. $^{74,75}$

The larger proportion of sulfated mucins we observed in Barrett's esophagus compared to gastric intestinal metaplasia, taken together with the morphologic characteristics, support previous evidence that Barrett's esophagus essentially represents the incomplete type of intestinal metaplasia. ${ }^{17,76}$ However, in all cases, cells other than goblet cells were found: Alcian blue-positive columnar cells accumulating acid mucins which might represent a 'pregoblet' intestinal phenotype, as well as periodic acid-Schiff-positive cells which might represent a 'normal' gastric phenotype. Small areas of complete intestinal metaplasia, with absorptive enterocytes displaying an eosinophilic cytoplasm and a welldefined brush border, were found in $54 \%$ of the Barrett's esophagus cases. These findings may contribute to settle the controversy about the origin of Barrett's esophagus because it has clear similarities to gastric intestinal metaplasia: in both locations small intestinal mucins are found although in very different proportions. These observations suggest that Barrett's esophagus may not always start as incomplete intestinal metaplasia. In the stomach, the evolution of intestinal metaplasia is very slow, lasting for decades. However, the accumulated experience strongly suggests that complete metaplasia makes its appearance first and then extends gradually in the gastric surface; incomplete metaplasia may or may not appear later, in older subjects. ${ }^{16}$ In the esophagus, the lesser proportion of complete intestinal metaplasia found suggests that the transformation to the incomplete phenotype takes place earlier in the process and overwhelms any original areas of complete metaplasia. Once established, however, the incomplete metaplasia phenotype is an indicator of high risk of dysplasia and cancer. These observations, taken together with reported morphometric criteria, have led to the suggestion that incomplete metaplasia is an early or 'mild' form of dysplasia. ${ }^{77}$

The mechanisms involved in the more rapid transition from complete to incomplete metaplasia in the esophagus as compared to the stomach are unknown. Most investigators believe that the main force driving the precancerous process in the stomach is $H$. pylori infection, ${ }^{78}$ while the driving force in the esophagus may be the acid-biliary reflux. ${ }^{79,80}$ Helicobacter carcinogenesis may be related to oxygen radicals generation at the tissue level. ${ }^{81,82}$ Bile, on the other hand, is considered a promoter of proliferation and carcinogenesis in susceptible cells. ${ }^{83}$

Our findings with mucin immunohistochemistry indicate that complete metaplasia is characterized by weak expression of (intestinal) MUC2 and absence of (gastric) MUC1, MUC5AC and MUC6. Incomplete metaplasia, including Barrett, displays strong expression of MUC1, MUC2 and MUC5AC.

Immunostaining with Das-1 antibody, a marker of colonic epithelium, is negative in complete metaplasia but strongly positive in incomplete metaplasia in both esophageal and gastric mucosa, data supporting previous observations. ${ }^{37,38}$

Complete metaplasia, therefore, represents predominantly 'pure' small intestinal antigens. Incomplete metaplasia, on the other hand, expresses small intestinal (MUC2) antigens, large intestinal (Das-1) and gastric (MUC1 and MUC5AC) antigens. These findings could be interpreted as supporting the hypothesis that loss of differentiation followed by redifferentiation could be observed in the carcinogenic process. ${ }^{42}$ This hypothesis proposes that the normal epithelium goes through a process of loss of differentiation, which could lead to the proliferation of stem cells, which then may be re-differentiated to diverse phenotypes. In the stomach the glandular epithelium loses its differentiation and the gastric 
stem cells differentiate towards an intestinal phenotype. This may support the 'common underlying mechanism' leading to the 'mixed gastrointestinal phenotype' described by Jass. ${ }^{21}$ In the esophagus the squamous epithelium is first destroyed by the acidbiliary reflux and the esophageal stem cells differentiate towards a glandular phenotype, more resistant than the squamous epithelium to the acid environment. $^{84}$

Our observations on cytokeratins indicate that the most useful marker is represented by cytokeratin 7 , which is absent in complete intestinal metaplasia, but very abundant in incomplete metaplasia. Cytokeratin 7 is a protein observed in fetal stomach, ${ }^{42,43}$ but absent in the normal adult gastric mucosa. Its expression in incomplete gastric metaplasia, ${ }^{42,85}$ in Barrett's epithelium, in dysplasia and in carcinoma again $^{47,86}$ fits well with loss of differentiation followed by redifferentiation hypothesis previously discussed in relation to the mucins expression. It also reinforces the idea that incomplete metaplasia may represent an initial phase of dysplasia. In addition, cytokeratin 7 neoexpression observed by us in deep microcysts in gastric intestinal metaplasia was described recently by Kirchner et $a l^{42}$ in patients with gastric adenocarcinoma and in an animal model of infection with $H$. pylori suggesting its role in the carcinogenic process.

Contrary to some reports of a typical 'Barrett's pattern' based on cytokeratins 7 and 20 expression, ${ }^{41}$ our results indicate that although strong and diffuse cytokeratin 7 expression is characteristic of Barrett's esophagus, cytokeratin 20 is not useful or determinant of a Barrett's pattern. Cytokeratin 20 expression displayed a superficial pattern similar in both BE and gastric intestinal metaplasia, irrespective of the type of intestinal metaplasia, supporting published data. ${ }^{87}$

The expression of cytokeratin 7 in the 'normal' cardia, previously reported, ${ }^{36,45}$ is an intriguing finding. It suggests that the cardia mucosa differs phenotypically and perhaps genotypically, from more distal gastric mucosa.

Our findings on the proliferation marker Ki-67 indicate that the superficial expansion of the replication zone is significantly greater in Barrett's esophagus than in gastric intestinal metaplasia. This is probably related to the fact that Barrett's esophagus natural history is shorter than that of gastric intestinal metaplasia: usually a few years for the former vs several decades for the latter. The worst prognosis of Barrett compared to that of gastric metaplasia may be represented by the higher Ki-67 labelling index leading to greater replication and superficial expansion of the replication zone. It appears that the mitogenic stimulus in the esophagus (bile salts?) is more potent than its gastric equivalent (H. pylori?).

Both Barrett's esophagus and gastric intestinal metaplasia are seen in a background of chronic active inflammation. Even though the causative agents may differ, chronic active inflammation may be causally associated with both entities. Clearing the infection and reinforcing the antioxidant defense mechanisms may delay the precancerous process. This is strongly supported by chemoprevention trials in humans. ${ }^{88,89}$

Our observations on inflammatory markers confirm previous report that inducible nitric oxide synthase, present in inflammatory cells, become expressed in the epithelial cells in the incomplete metaplasia seen in Barrett's esophagus as well as dysplastic and carcinoma cells. ${ }^{54,82}$ Cyclooxygenase2 is also seen in these lesions, but can also be found in complete metaplasia. No clear explanation has been offered for the role of such markers in epithelial cells, but it does suggest a role as promoters of carcinogenesis. Decreasing the impact of inflammation may contribute to prevention of Barrett preceded adenocarcinoma. Several studies using cyclooxygenase-2 inhibitors strongly support that notion. ${ }^{90-92}$

From the pathology practice point of view, our findings suggest that the expressions of MUC1, MUC5AC (gastric), Das-1 (colonic) and cytokeratin 7 are excellent markers of incomplete metaplasia and Barrett's esophagus. Their intensity and the extent of expression, in addition to that of MUC2, Ki-67, inducible nitric oxide synthase and cyclooxygenase-2, may aid in the evaluation of the patient's risk of dysplasia and carcinoma, thereby facilitating clinical management.

\section{Acknowledgements}

This work was supported by Louisiana Board of Regents Grant HEF (2000-05)-03.

\section{References}

1 Parkin DM, Bray FI, Devesa SS. Cancer burden in the year 2000. The global picture. Eur J Cancer 2001;37(Suppl 8):S4-S66.

2 Parkin DM, Bray FI, Devesa SS. Corrigendum to 'Cancer burden in the year 2000. The global picture' [Eur J Cancer (2001) 37(Suppl 8) S4-S66]. Eur J Cancer 2003;39:848.

3 Bytzer P, Christensen PB, Damkier P, et al. Adenocarcinoma of the esophagus and Barrett's esophagus: a population-based study. Am J Gastroenterol 1999;94:86-91.

4 Devesa SS, Blot WJ, Fraumeni Jr JF. Changing patterns in the incidence of esophageal and gastric carcinoma in the United States. Cancer 1998;83:2049-2053.

5 Newnham A, Quinn MJ, Babb P, et al. Trends in the subsite and morphology of oesophageal and gastric cancer in England and Wales 1971-1998. Aliment Pharmacol Ther 2003;17:665-676.

6 Pera M, Pera M. Recent changes in the epidemiology of esophageal cancer. Surg Oncol 2001;10:81-90.

7 El Serag HB, Mason AC, Petersen N, et al. Epidemiological differences between adenocarcinoma of the 
oesophagus and adenocarcinoma of the gastric cardia in the USA. Gut 2002;50:368-372.

8 Allison P, Johnstone A. The oesophagus lined with gastric mucous membrane. Thorax 1953;8:87-101.

9 Barrett N. The lower esophagus lined by columnar epithelium. Surgery 1957;41:881-894.

10 Paull A, Trier JS, Dalton MD, et al. The histologic spectrum of Barrett's esophagus. N Engl J Med 1976;295:476-480.

11 Goldblum JR. Barrett's esophagus and Barrett's-related dysplasia. Mod Pathol 2003;16:316-324.

12 Sampliner RE. Updated guidelines for the diagnosis, surveillance, and therapy of Barrett's esophagus. Am J Gastroenterol 2002;97:1888-1895.

13 Cameron AJ, Ott BJ, Payne WS. The incidence of adenocarcinoma in columnar-lined (Barrett's) esophagus. N Engl J Med 1985;313:857-859.

14 Correa P, Haenszel W, Cuello C, et al. A model for gastric cancer epidemiology. Lancet 1975;2:58-60.

15 Correa P. A human model of gastric carcinogenesis. Cancer Res 1988;48:3554-3560.

16 Filipe MI, Munoz N, Matko I, et al. Intestinal metaplasia types and the risk of gastric cancer: a cohort study in Slovenia. Int J Cancer 1994;57:324329.

17 Haggitt RC. Barrett's esophagus, dysplasia, and adenocarcinoma. Hum Pathol 1994;25:982-993.

18 Ruol A, Parenti A, Zaninotto G, et al. Intestinal metaplasia is the probable common precursor of adenocarcinoma in Barrett's esophagus and adenocarcinoma of the gastric cardia. Cancer 2000;88:25202528.

19 You WC, Li JY, Blot WJ, et al. Evolution of precancerous lesions in a rural Chinese population at high risk of gastric cancer. Int J Cancer 1999;83:615-619.

20 Dekker J, Rossen JW, Buller HA, et al. The MUC family: an obituary. Trends Biochem Sci 2002;27:126-131.

21 Jass JR. Mucins in the gastrointestinal tract: their role in the pathogenesis and as diagnostic markers. Annual Meeting of the United States and Canadian Academy of Pathology. March 22-28 2003.

22 Arul GS, Moorghen M, Myerscough N, et al. Mucin gene expression in Barrett's oesophagus: an in situ hybridisation and immunohistochemical study. Gut 2000;47:753-761.

23 Carrato C, Balague C, de Bolos C, et al. Differential apomucin expression in normal and neoplastic human gastrointestinal tissues. Gastroenterology 1994;107:160-172.

24 Guillem P, Billeret V, Buisine MP, et al. Mucin gene expression and cell differentiation in human normal, premalignant and malignant esophagus. Int J Cancer 2000;88:856-861.

25 Reis CA, David L, Correa P, et al. Intestinal metaplasia of human stomach displays distinct patterns of mucin (MUC1, MUC2, MUC5AC, and MUC6) expression. Cancer Res 1999;59:1003-1007.

26 Reis CA, David L, Carvalho F, et al. Immunohistochemical study of the expression of MUC6 mucin and co-expression of other secreted mucins (MUC5AC and MUC2) in human gastric carcinomas. J Histochem Cytochem 2000;48:377-388.

27 Chinyama CN, Marshall RE, Owen WJ, et al. Expression of MUC1 and MUC2 mucin gene products in Barrett's metaplasia, dysplasia and adenocarcinoma: an immunopathological study with clinical correlation. Histopathology 1999;35:517-524.
28 Warson C, Van De Bovenkamp JH, Korteland-Van Male $\mathrm{AM}$, et al. Barrett's esophagus is characterized by expression of gastric-type mucins (MUC5AC, MUC6) and TFF peptides (TFF1 and TFF2), but the risk of carcinoma development may be indicated by the intestinal-type mucin, MUC2. Hum Pathol 2002;33:660-668.

29 Silva E, Teixeira A, David L, et al. Mucins as key molecules for the classification of intestinal metaplasia of the stomach. Virchows Arch 2002;440:311-317.

30 Teixeira A, David L, Reis CA, et al. Expression of mucins (MUC1, MUC2, MUC5AC, and MUC6) and type 1 Lewis antigens in cases with and without Helicobacter pylori colonization in metaplastic glands of the human stomach. J Pathol 2002;197:37-43.

31 Lee HS, Lee HK, Kim HS, et al. MUC1, MUC2, MUC5AC, and MUC6 expressions in gastric carcinomas: their roles as prognostic indicators. Cancer 2001;92:1427-1434.

32 Pinto-de-Sousa J, David L, Reis CA, et al. Mucins MUC1, MUC2, MUC5AC and MUC6 expression in the evaluation of differentiation and clinico-biological behaviour of gastric carcinoma. Virchows Arch 2002;440:304-310.

33 Das KM, Sakamaki S, Vecchi M, et al. The production and characterization of monoclonal antibodies to a human colonic antigen associated with ulcerative colitis: cellular localization of the antigen by using the monoclonal antibody. J Immunol 1987;139:77-84.

34 Kesari KV, Yoshizaki N, Geng X, et al. Externalization of tropomyosin isoform 5 in colon epithelial cells. Clin Exp Immunol 1999;118:219-227.

35 Das KM, Prasad I, Garla S, et al. Detection of a shared colon epithelial epitope on Barrett epithelium by a novel monoclonal antibody. Ann Intern Med 1994;120:753-756.

36 DeMeester SR, Wickramasinghe KS, Lord RV, et al. Cytokeratin and DAS-1 immunostaining reveal similarities among cardiac mucosa, CIM, and Barrett's esophagus. Am J Gastroenterol 2002;97:2514-2523.

37 Glickman JN, Wang H, Das KM, et al. Phenotype of Barrett's esophagus and intestinal metaplasia of the distal esophagus and gastroesophageal junction: an immunohistochemical study of cytokeratins 7 and 20, Das-1 and 45 MI. Am J Surg Pathol 2001;25:87-94.

38 Das K, Slate J, Ramsundar L. Gastric intestinal metaplasia with colonic phenotype, as detected by a novel biomarker, mAb Das-1, is highly associated with gastric carcinoma. Gastroenterology 2000;118:A273 [abstract].

39 Moll R, Franke WW, Schiller DL, et al. The catalog of human cytokeratins: patterns of expression in normal epithelia, tumors and cultured cells. Cell 1982;31:1124.

40 Moll R, Schiller DL, Franke WW. Identification of protein IT of the intestinal cytoskeleton as a novel type I cytokeratin with unusual properties and expression patterns. J Cell Biol 1990;111:567-580.

41 Ormsby AH, Goldblum JR, Rice TW, et al. Cytokeratin subsets can reliably distinguish Barrett's esophagus from intestinal metaplasia of the stomach. Hum Pathol 1999;30:288-294.

42 Kirchner T, Muller S, Hattori T, et al. Metaplasia, intraepithelial neoplasia and early cancer of the stomach are related to dedifferentiated epithelial cells defined by cytokeratin-7 expression in gastritis. Virchows Arch 2001;439:512-522. 
43 Stosiek P, Brautigam E, Kasper M. Expression of cytokeratin 7 in human glandular epithelium of fetal stomach. Acta Histochem 1991;91:21-23.

44 Moll R, Lowe A, Laufer J, et al. Cytokeratin 20 in human carcinomas. A new histodiagnostic marker detected by monoclonal antibodies. Am J Pathol 1992;140:427-447.

45 Jovanovic I, Tzardi M, Mouzas IA, et al. Changing pattern of cytokeratin 7 and 20 expression from normal epithelium to intestinal metaplasia of the gastric mucosa and gastroesophageal junction. Histol Histopathol 2002;17:445-454.

46 Ormsby AH, Goldblum JR, Rice TW, et al. The utility of cytokeratin subsets in distinguishing Barrett's-related oesophageal adenocarcinoma from gastric adenocarcinoma. Histopathology 2001;38:307-311.

47 Park SY, Kim HS, Hong EK, et al. Expression of cytokeratins 7 and 20 in primary carcinomas of the stomach and colorectum and their value in the differential diagnosis of metastatic carcinomas to the ovary. Hum Pathol 2002;33:1078-1085.

48 El Zimaity HM, Graham DY. Cytokeratin subsets for distinguishing Barrett's esophagus from intestinal metaplasia in the cardia using endoscopic biopsy specimens. Am J Gastroenterol 2001;96:1378-1382.

49 Wilson KT. Angiogenic markers, neovascularization and malignant deformation of Barrett's esophagus. Dis Esophagus 2002;15:16-21.

50 Cheong E, Igali L, Harvey I, et al. Cyclo-oxygenase-2 expression in Barrett's oesophageal carcinogenesis: an immunohistochemical study. Aliment Pharmacol Ther 2003;17:379-386.

51 Morris CD, Armstrong GR, Bigley G, et al. Cyclooxygenase-2 expression in the Barrett's metaplasiadysplasia-adenocarcinoma sequence. Am J Gastroenterol 2001;96:990-996.

52 Rajnakova A, Moochhala S, Goh PM, et al. Expression of nitric oxide synthase, cyclooxygenase, and p53 in different stages of human gastric cancer. Cancer Lett 2001;172:177-185.

53 Son HJ, Kim YH, Park DI, et al. Interaction between cyclooxygenase-2 and inducible nitric oxide synthase in gastric cancer. J Clin Gastroenterol 2001;33:383-388.

54 Wilson KT, Fu S, Ramanujam KS, et al. Increased expression of inducible nitric oxide synthase and cyclooxygenase-2 in Barrett's esophagus and associated adenocarcinomas. Cancer Res 1998;58:29292934.

55 Yamagata R, Shimoyama T, Fukuda S, et al. Cyclooxygenase-2 expression is increased in early intestinaltype gastric cancer and gastric mucosa with intestinal metaplasia. Eur J Gastroenterol Hepatol 2002;14:359363.

56 Gerdes J, Schwab U, Lemke H, et al. Production of a mouse monoclonal antibody reactive with a human nuclear antigen associated with cell proliferation. Int J Cancer 1983;31:13-20.

57 Schmidt MH, Broll R, Bruch HP, et al. The proliferation marker pKi-67 organizes the nucleolus during the cell cycle depending on Ran and cyclin B. J Pathol 2003;199:18-27.

58 Hong MK, Laskin WB, Herman BE, et al. Expansion of the Ki-67 proliferative compartment correlates with degree of dysplasia in Barrett's esophagus. Cancer 1995;75:423-429.

59 Ishida M, Gomyo Y, Tatebe S, et al. Apoptosis in human gastric mucosa, chronic gastritis, dysplasia and carcinoma: analysis by terminal deoxynucleotidyl transferase-mediated dUTP-biotin nick end labelling. Virchows Arch 1996;428:229-235.

60 Miracco C, Spina D, Vindigni C, et al. Cell proliferation patterns and p53 expression in gastric dysplasia. Int J Cancer 1995;62:149-154.

61 Whittles CE, Biddlestone LR, Burton A, et al. Apoptotic and proliferative activity in the neoplastic progression of Barrett's oesophagus: a comparative study. J Pathol 1999;187:535-540.

62 Prophet E, Mills B, Arrington J, et al. Laboratory Methods in Histotechnology. Washington, DC: American Registry of Pathology, 1994.

63 Spicer S. Diamine methods for differentiating mucosubstances histochemically. J Histochem Cytochem 1965;8:211-234.

64 Garvey W, Fathi A, Bigelow F. Modified Steiner for the demonstration of spirochetes. J Histotechnol 1985;8:15-17.

65 Taylor-Papadimitriou J, Peterson JA, Arklie J, et al. Monoclonal antibodies to epithelium-specific components of the human milk fat globule membrane: production and reaction with cells in culture. Int J Cancer 1981;28:17-21.

66 Riddell RH, Goldman H, Ransohoff DF, et al . Dysplasia in inflammatory bowel disease: standardized classification with provisional clinical applications. Hum Pathol 1983;14:931-968.

67 Rugge M, Correa P, Dixon MF, et al. Gastric dysplasia: the Padova international classification. Am J Surg Pathol 2000;24:167-176.

68 Correa P, Haenszel W, Cuello C, et al. Gastric precancerous process in a high risk population: cohort follow-up. Cancer Res 1990;50:4737-4740.

69 Correa P, Haenszel W, Cuello C, et al. Gastric precancerous process in a high risk population: cross-sectional studies. Cancer Res 1990;50:47314736.

70 Matsukura N, Suzuki K, Kawachi T, et al. Distribution of marker enzymes and mucin in intestinal metaplasia in human stomach and relation to complete and incomplete types of intestinal metaplasia to minute gastric carcinomas. J Natl Cancer Inst 1980;65:231240.

71 Teglbjaerg PS, Nielsen HO. 'Small intestinal type' and 'colonic type' intestinal metaplasia of the human stomach, and their relationship to the histogenetic types of gastric adenocarcinoma. Acta Pathol Microbiol Scand [A] 1978;86A:351-355.

72 Heilmann KL, Hopker WW. Loss of differentiation in intestinal metaplasia in cancerous stomachs. A comparative morphologic study. Pathol Res Pract 1979;164:249-258.

73 Dixon MF, Genta RM, Yardley JH, et al. Classification and grading of gastritis. The updated Sydney System. International Workshop on the Histopathology of Gastritis, Houston 1994. Am J Surg Pathol 1996;20:1161-1181.

74 Silva S, Filipe MI, Pinho A. Variants of intestinal metaplasia in the evolution of chronic atrophic gastritis and gastric ulcer. A follow up study. Gut 1990;31:1097-1104.

75 Rokkas T, Filipe MI, Sladen GE. Detection of an increased incidence of early gastric cancer in patients with intestinal metaplasia type III who are closely followed up. Gut 1991;32:1110-1113. 
76 Jass JR. Mucin histochemistry of the columnar epithelium of the oesophagus: a retrospective study. J Clin Pathol 1981;34:866-870.

77 Tosi P, Filipe MI, Luzi P, et al. Gastric intestinal metaplasia type III cases are classified as low-grade dysplasia on the basis of morphometry. J Pathol 1993;169:73-78.

78 Kelley JR, Duggan JM. Gastric cancer epidemiology and risk factors. J Clin Epidemiol 2003;56:1-9.

79 Dixon MF, Neville PM, Mapstone NP, et al. Bile reflux gastritis and Barrett's oesophagus: further evidence of a role for duodenogastro-oesophageal reflux? Gut 2001;49:359-363.

80 Zaninotto G, Portale G, Parenti A, et al. Role of acid and bile reflux in development of specialised intestinal metaplasia in distal oesophagus. Dig Liver Dis 2002;34:251-257

81 Farinati F, Cardin R, Russo VM. Helicobacter pylori CagA status, mucosal oxidative damage and gastritis phenotype: a potential pathway to cancer? Helicobacter 2003;8:227-234.

82 Pignatelli B, Bancel B, Esteve J, et al. Inducible nitric oxide synthase, anti-oxidant enzymes and Helicobacter pylori infection in gastritis and gastric precancerous lesions in humans. Eur J Cancer Prev 1998;7:439447.

83 Kaur BS, Triadafilopoulos G. Acid- and bile-induced PGE(2) release and hyperproliferation in Barrett's esophagus are COX-2 and PKC-epsilon dependent. Am J Physiol Gastrointest Liver Physiol 2002;283:G327-G334.

84 Richter JE. Importance of bile reflux in Barrett's esophagus. Dig Dis 2000;18:208-216.
85 Petraki K, Mantzaris GJ, Petraki C. Immunohistochemical expression of cytokeratins 7 and 20 in gastric intestinal metaplasia and in Barrett's esophagus. Gastroenterology 2000;118:A226 [abstract].

86 Chu P, Wu E, Weiss LM. Cytokeratin 7 and cytokeratin 20 expression in epithelial neoplasms: a survey of 435 cases. Mod Pathol 2000;13:962-972.

87 Schwerer MJ, Baczako K. Immunohistochemical evaluation of keratin 20 expression in intestinal metaplasia types I to III. J Clin Pathol 1996;49:791-794.

88 Blot WJ, Li JY, Taylor PR, et al. Nutrition intervention trials in Linxian, China: supplementation with specific vitamin/mineral combinations, cancer incidence, and disease-specific mortality in the general population. J Natl Cancer Inst 1993;85:1483-1492.

89 Correa P, Fontham ET, Bravo JC, et al. Chemoprevention of gastric dysplasia: randomized trial of antioxidant supplements and anti-Helicobacter pylori therapy. J Natl Cancer Inst 2000;92:1881-1888.

90 Buttar NS, Wang KK, Anderson MA, et al. The effect of selective cyclooxygenase-2 inhibition in Barrett's esophagus epithelium: an in vitro study. J Natl Cancer Inst 2002;94:422-429.

91 Buttar NS, Wang KK, Leontovich O, et al. Chemoprevention of esophageal adenocarcinoma by COX-2 inhibitors in an animal model of Barrett's esophagus. Gastroenterology 2002;122:1101-1112.

92 Kaur BS, Khamnehei N, Iravani M. Rofecoxib inhibits cyclooxygenase 2 expression and activity and reduces cell proliferation in Barrett's esophagus. Gastroenterology 2002;123:60-67. 